\title{
The curious connection between COVID-19 and antioxidants
}

\author{
Annie Kathuria ${ }^{1}$
}

${ }^{1}$ Affiliation not available

May 5, 2020

The COVID19 virus has plagued the world, as a cellular and molecular biologist, I am presenting this commentary after careful analysis of the genomic structure of the virus and its effects on the lungs.

Why does it affect the older generation more compared to young adults and children?

The free radical theory of aging proposes that organisms age because they accumulate oxidative damage ${ }^{1-3}$. I postulate this causes the older population to have an increase in reactive oxygen species (ROS) ${ }^{4-7}$, which partially reduces metabolites of molecular oxygen generated as by-products of various cellular processes, such as respiration ${ }^{1,8}$. This creates a condition of hypoxia, particularly in the lungs as the lung volume and capacity decreases with age $^{9}$.Another interesting phenomena to note is that severe acute respiratory syndrome (SARS-CoV) virus, which is genetically similar to corona virus, are known to proliferate in hypoxia conditions. Hence, making the older generation more susceptible to disease.

Another point to be noted is the lungs are highly vulnerable to viral infection as the express increased cell surface proteins that the viruses use to gain entry into the cell ${ }^{10}$. Latest research shows that ACE2 (Angiotensin-converting enzyme 2) has been identified as a potential SARS-CoV2 receptor and is highly expressed in the lungs ${ }^{11-12}$. One of the severe manifestations of corona virus is lung fibrosis, even when the patient is recovered, the lung function declines by $20-30 \%{ }^{13-15}$. The initiation of lung fibrosis occurs as ROS species are generated by NADPH oxidase-4 (NOX4), the pathway it triggers is angiotensin II (AngII) type 1 receptor (AT1R) axis which causes increased ROS production in lung fibroblasts ${ }^{16}$. Angiotensin-converting enzyme 2 (ACE2) counteracts this inhibition via the RhoA/Rock pathway by reducing NOX4-derived ROS ${ }^{16}$. My hypothesis is that as the SARS-CoV2 virus enters the bloodstream, infecting the lung cells, it uses all the available ACE2 receptors, which causes an elevation in AngII-AT1R axis, which leads to activation of NOX4-derived ROS-mediated RhoA/Rock pathway, creating a hypoxic environment, this further facilitates viral multiplication and causes chronic obstructive in the lungs. Therefore, pharmacological antioxidants can act as potential drug targets in this scenario.

In layman's terms- for this virus to multiply, it requires hypoxic conditions and it creates this by attacking the lung surface protein that prevents hypoxia. Potentially, if we have more antioxidants in our body the lesser chance of the virus finding the ideal conditions to proliferate. 


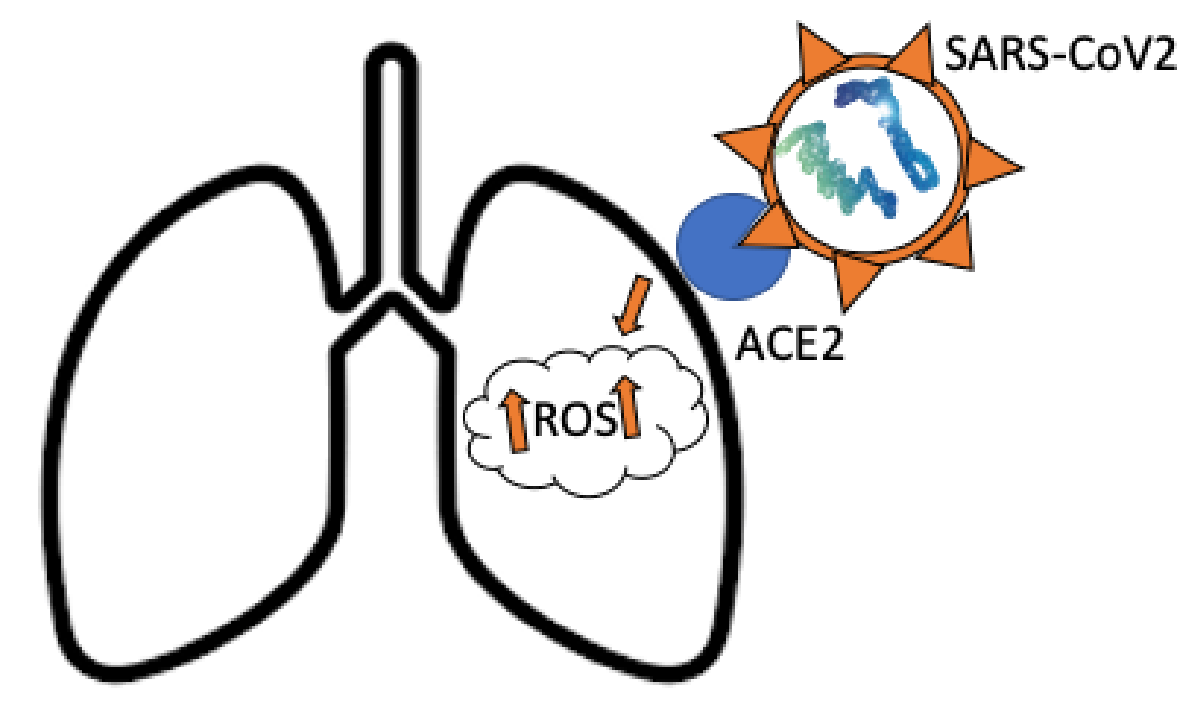

References:

1. Gladyshev VN. The free radical theory of aging is dead. Long live the damage theory!. Antioxid Redox Signal :20(4):727-731. 2014.

2. Sohal RS. and Weindruch R. Oxidative stress, caloric restriction, and aging. Science 273: 59-63, 1996.

3. Speakman JR. and Selman C. The free-radical damage theory: accumulating evidence against a simple link of oxidative stress to ageing and lifespan. Bioessays 33: 255-259, 2011.

4. Lam YT. Critical Roles of Reactive Oxygen Species in Age-Related Impairment in IschemiaInduced Neovascularization by Regulating Stem and Progenitor Cell Function. Oxid Med Cell Longev .2015:7095901. 2015/

5. Luceri C, Bigagli E, Femia AP, Caderni G, Giovannelli L, Lodovici M. Aging related changes in circulating reactive oxygen species (ROS) and protein carbonyls are indicative of liver oxidative injury. Toxicol Rep . 2017;5:141-145. 2017.

6. Tan BL, Norhaizan ME, Liew W-P-P, Sulaiman Rahman H Antioxidant and Oxidative Stress: A Mutual Interplay in Age-Related Diseases. Front Pharmacol 9:1162. 2018.

7. Burtenshaw D, Kitching M, Redmond EM, Megson IL, Cahill PA Reactive Oxygen Species (ROS), Intimal Thickening, and Subclinical Atherosclerotic Disease. Front Cardiovasc Med 6:89.2019.

8. Blagosklonny MV. Aging: ROS or TOR. Cell Cycle 7: 3344-3354, 2008.

9. Sharma, Gulshan, and James Goodwin. "Effect of aging on respiratory system physiology and immunology." Clinical interventions in aging vol. 1,3 253-60.2006.

10. Alberts B, Johnson A, Lewis J, et al. Molecular Biology of the Cell. 4th edition. New York: Garland Science; 2002. Cell Biology of Infection

11. Li, W., Moore, M., Vasilieva, N. et al. Angiotensin-converting enzyme 2 is a functional receptor for the SARS coronavirus. Nature 426, 450-454 (2003).

12. Lu R et al. (2020) Genomic characterisation and epidemiology of novel coronavirus: implications for virus origins and receptor binding. Lancet 395:565-574. 2019.

13. https://www.theguardian.com/world/2020/mar/23/coronavirus-what-happens-to-peoples-lungs-if-theyget-covid-19

14. https://health.clevelandclinic.org/heres-the-damage-coronavirus-covid-19-can-do-to-your-lungs/

15. https://www.dw.com/en/covid-19-recovered-patients-have-partially-reduced-lung-function/a52859671

16. Dikalov SI, Nazarewicz RR. Angiotensin II-induced production of mitochondrial reactive oxygen species: potential mechanisms and relevance for cardiovascular disease. Antioxid Redox Signal .;19(10):1085-1094. 2013. 